\title{
A FORMAÇÃO CONTINUADA NA PERSPECTIVA DA GESTẪO E DA PRÁTICA NA SALA DE AULA
}

\author{
http://dx.doi.org/10.5902/2176217111717
}

\author{
Severino Roberto de Lima \\ Secretaria Estadual da Educação e Cultura do \\ Estado do Tocantins, Brasil.
}

\begin{abstract}
Resumo
Este trabalho apresenta resultados referentes à gestão do processo de Formação Continuada e a prática em sala de aula dos professores de matemática no ensino médio estadual em Palmas-TO, política de valorização profissional. Como metodologia utilizou-se a pesquisa qualitativa estruturada a partir de estudos bibliográficos e pesquisa de campo. O objetivo foi verificar se essas políticas residem como possibilidades para o fortalecimento da gestão escolar e, se têm correspondido aos anseios e expectativas desses profissionais em educação. Embora saibamos que a formação continuada é um processo contínuo, percebem-se, como possibilidades dessa formação, novas habilidades, planejamento participativo, envolvimento nas ações pedagógicas, participação na gestão e prática reflexiva em sala de aula.

Palavras-chave: gestão educacional, formação continuada, matemática.
\end{abstract}

\section{THE CONTINUING EDUCATION IN VIEW OF MANAGEMENT AND PRACTICE IN THE CLASSROOM}

\begin{abstract}
This paper presents results regarding the management of the Continuing Education and practical classroom math teachers in high school state Palmas-TO policy professional development. The methodology used was qualitative research from structured bibliographic studies and field research. The goal was to determine whether these policies reside as possibilities for strengthening school management and have been matched to the desires and expectations of professionals in education. Although we know that continuing education is an ongoing process, perceive themselves as possibilities of training, new skills, participatory planning, involvement in pedagogical actions, participation in management and reflective practice in the classroom.

Key-words: education management, continuing education, mathematics.
\end{abstract}




\section{Introdução}

$O$ atual sistema de ensino brasileiro resulta de grandes mudanças consideradas importantes no processo de reforma do Estado, portanto, resultado das alterações concretizadas em 1988, pela promulgação da Constituição da República Federativa do Brasil, em 1996, por meio da aprovação da Lei de Diretrizes e Bases da Educação Nacional (lei n. 9.394/96), e também da aprovação do Plano Nacional da Educação.

As leis citadas foram aprovadas com o objetivo de garantir as diretrizes e bases para a educação nacional, estabelecendo normas e procedimentos para a organização da gestão educacional e dos diferentes níveis e modalidades da educação. Buscam, também, fortalecer os programas e ações a serem implantados, propiciando o acesso, a permanência do aluno na escola com sucesso e, principalmente, uma gestão democrática. É com essa ótica que a União, por meio do Ministério da Educação, em parceria com os governos estaduais e municipais, busca garantir a educação como um direito social do cidadão.

A educação, segundo a Constituição Federal do Brasil de 1988, constitui um direito social, visando ao pleno desenvolvimento da pessoa, seu preparo para o exercício da cidadania e sua qualificação para o trabalho. Ainda estabelece como direitos e deveres delimitar competências e atribuições, regular o financiamento e definir princípios como pluralismo, liberdade e uma gestão democrática. Nesse entendimento, o Ministério da Educação tenta minimizar os problemas da desigualdade social no país.

É pensando nesses problemas que o Ministério da Educação, Estados e Municípios desenvolvem ações no sentido de implementar políticas que possam contribuir para a melhoria dos processos de gestão da educação básica, tais como: adequação das escolas aos padrões mínimos exigidos; participação contínua da comunidade nas atividades escolares; conselho escolar democrático, participativo e atuante; planejamento participativo na elaboração dos projetos; aplicação dos recursos financeiros respeitando as prioridades; implantação de políticas de formação, valorização e profissionalização docente. Um exemplo dessas políticas é o Plano de Ações Articuladas, que contribuí para o fortalecimento das políticas educacionais e o desenvolvimento da gestão democrática em suas quatro dimensões: infra-estrutura e recursos pedagógicos, formação de professores e profissionais de serviços e apoio escolar, gestão educacional e práticas pedagógicas.

Dentre as quatro dimensões apresentadas, o foco desse trabalho está voltado para as dimensões II Formação de professores e III Gestão educacional. Nesse contexto, o Plano de Desenvolvimento da Educação, apresentado pelo Ministério da Educação em abril de 2007, colocou à disposição dos Estados, Municípios e Distrito Federal, instrumentos de avaliação e de implementação de políticas educacionais com vistas à melhoria da qualidade da educação, sobretudo o desenvolvimento social, econômico e da profissionalização dos docentes da educação básica.

O objetivo principal desse trabalho foi verificar se a política de formação continuada proposta pela Seduc-TO tem contribuído para o fortalecimento da gestão escolar e, principalmente, se têm correspondido aos anseios e expectativas dos profissionais em educação. Para tanto foi preciso entender como os professores de Matemática compreendem o processo de gestão da formação continuada e investigar como os 
professores percebem a formação continuada. Além disso, procurou-se saber se esses profissionais aplicam o que aprenderam na formação continuada em sala de aula.

É necessário entender a importância das atuais políticas de gestão educacional e a necessidade de ofertar cursos de formação continuada para os profissionais em Matemática. Para tanto, espera-se que posições políticas possam ser assumidas com base em sólida fundamentação acadêmica, que mesmo provisórias incorporem o conhecimento historicamente acumulado sobre gestão e a profissão docente.

Para que o trabalho realizado pelo professor de Matemática na sala de aula contribua para uma gestão educacional de sucesso e implique em aprendizagem, tornase indispensável tentar aproximar os conceitos e conteúdos matemáticos aos temas significativos do mundo atual, veiculando-os às questões práticas do dia-a-dia e a realidade do aluno. Nesse contexto, faz-se necessário uma política de fortalecimento à formação continuada para os docentes.

Pensando nessa perspectiva, uma das propostas da Secretaria Estadual da Educação do Tocantins é propor uma formação de qualidade para os docentes licenciados em Matemática. Com este propósito, a Seduc-TO desenvolve uma política de formação denominada Programa de Capacitação para os Professores da Educação Básica do Tocantins, a partir da proposta curricular elaborada com a participação dos professores, técnicos administrativos das escolas, diretorias regionais de ensino e SeducTO.

Mesmo com esta política de formação percebe-se um mal estar e um significativo nível de insatisfação, manifestação de dúvidas e insegurança desses profissionais. Tal situação pode evidenciar que a formação continuada oferecida talvez não esteja diretamente relacionada com as necessidades vivenciadas na prática do dia-a-dia da sala de aula.

Diante do cenário apresentado, podemos perguntar: como acontece a gestão do processo de formação continuada e a prática em sala de aula dos professores de matemática do ensino médio estadual em Palmas - Tocantins?

O desenvolvimento deste trabalho foi realizado a partir de pesquisa de campo em quatro Centros de Ensino Médio Estadual em Palmas - Tocantins, no primeiro semestre de 2011, e teve como procedimento metodológico a aplicação de questionário com questões objetivas focando o processo de formação continuada dos professores de Matemática do ensino médio estadual de Palmas, suas contribuições para 0 fortalecimento da gestão educacional, bem como seus reflexos na sala de aula. A partir daí, buscou-se analisar o processo de gestão educacional relacionado à formação continuada e à prática docente desses profissionais em educação, descrevendo as necessidades e expectativas em relação à política de formação continuada.

\section{Gestão democrática e formação continuada}

Desde o início da década de 1980 o tema da gestão da escola e sua autonomia ganhou destaque nos debates sobre escola pública. Mas o processo de reconstrução democrática não foi o único nem o primeiro momento em que o tema da gestão da escola foi ponto relevante nos debates político-educacional. Em décadas anteriores, quando a escola pública era constituída, em quase todos os Estados e municípios, por estruturas administrativas centralizadas e burocratizadas, ganhou força a reivindicação dos 
educadores pela autonomia escolar vinculada à necessidade de experimentar novas alternativas pedagógicas, curriculares e didáticas, objetivando diminuir os altos índices de evasão escolar e reprovação dos alunos (Warde, 1992). Nesse sentido, a política de formação continuada ofertada pela Seduc-TO pretende dinamizar, contextualizar, criar novas situações problematizando todo contexto histórico do dia-a-dia da sala de aula, mas, sobretudo, promover uma gestão reflexiva, participativa e homogênea entre professores, gestores e alunos.

Vygotsky (1989) deixa claro que é na interação social que o indivíduo vai se desenvolver no aspecto cultural e social e que a aprendizagem boa é a que se antecipa ao desenvolvimento humano, de modo que esteja intimamente relacionado ao contexto sociocultural o qual a pessoa está inserida.

Portanto, entende-se que cabe à gestão escolar a articulação e execução das políticas educacionais e a proposta pedagógica da escola, construindo com a comunidade escolar as ações de formação continuada na escola, que atendam as necessidades dos alunos e da escola, de forma que possa contribuir para o enriquecimento da prática docente em sala de aula e a promoção dos alunos, tanto na aprendizagem, como, no âmbito afetivo, social, cultural e para a vida. É com esse objetivo que o Ministério da Educação implantou políticas educacionais e estratégias como mecanismos para estimular a melhoria da qualidade do ensino, a busca por formação, profissionalização e qualificação contínua dos profissionais da educação.

O sistema nacional de educação, o campo das políticas educacionais, a formação, o desenvolvimento profissional e a valorização dos trabalhadores da educação sempre estiveram presentes nas agendas das grandes discussões temáticas. A formação dos profissionais da educação deve ser entendida na perspectiva social e alçada ao nível da política pública, tratada como direito e superando o estágio das iniciativas individuais para aperfeiçoamento próprio.

Ao analisarmos as questões que pontilham o ensino da Matemática é necessário que levemos em consideração o papel que é destinado ao professor, pois não é fácil reformular conceitos trazidos pelos tradicionais e tecnicistas da educação. Diante de tantas dificuldades e deficiências vivenciadas na educação em nossas escolas, o professor é responsabilizado pelo fracasso do aluno. De fato, ele é a mola mestra da educação e responsável direto pela formação do aluno. É sobre ele que recai a culpa pelo fracasso escolar ignorando as divergências sociais e econômicas do país.

De acordo com Lück (2004), a capacitação profissional constitui-se em um processo sistemático e organizado de promoção do desenvolvimento de conhecimentos, habilidades e atitudes necessárias para o correto exercício das atividades profissionais. É uma promoção de forma associada, em busca de um saber teórico ao prático, num determinado domínio. Essa capacitação precisa ser exercida fundamentalmente, de modo a desenvolver o senso de responsabilidade para a transformação e melhoria das práticas profissionais.

Segundo Lück (1997) política afirmativa da educação é aquela que reconhece a verdadeira importância das ações de formação continuada para o aprimoramento e a valorização dos profissionais em educação que atuam na escola, criando espaço adequado e possibilidades que favoreçam e propiciem o desenvolvimento dessas ações. 
São estratégias que irão valorizar a gestão educacional, como forma de fortalecimento institucional e de melhoria dos resultados na aprendizagem dos alunos.

A formação continuada dos professores refere-se às práticas profissionais do dia-adia em sala de aula, o que nos leva a dizer que os professores capazes de explicitar e de analisar sua prática docente, tirarão melhor proveito dessas modalidades de formação (Perrenoud, 2000).

Neste sentido, a proposta da Secretaria da Educação é oferecer um aprofundamento teórico vinculado a uma concepção de formação continuada em serviço, que buscará desenvolver um pensamento autônomo, numa perspectiva crítico-reflexiva quanto a concepção de aprendizagem, conteúdos e metodologia trabalhada.

Estudos de Zabala (1998; 1999; 2002), D`Ambrósio (2005) e Lopes (2005), constatam a insuficiente apropriação de conhecimentos nas diversas análises do desempenho docente e discente nas escolas públicas. Evidencia-se que é preciso trabalhar de forma efetiva com os professores todos os conteúdos aos quais eles não tiveram acesso em sua formação inicial. Isto demonstra que a educação continuada apresenta uma abordagem bem ampla, ao realizar a incorporação das noções básicas anteriormente utilizadas.

O que se percebe é que esses docentes receberam formação por referenciais culturais ou epistemológicos mediados por estruturas muitas vezes fragmentadas por múltiplas disciplinas, pelas quais se aprende a ver, ler e interpretar o mundo como ele é, de um modo também fragmentado, resultante dessa disposição compartimentada que se faz do saber em matérias como a forma única de apresentar e organizar o currículo escolar, alerta (Zabala, 2002).

A formação em exercício docente deve valorizar os professores e as escolas como capazes de pensar, de articular os saberes científicos, pedagógicos e da experiência na construção e na proposição das transformações necessárias às práticas escolares e às formas de organização dos espaços de ensinar e de aprender (Pimenta, 2002).

Portanto, entende-se que este é o compromisso da Secretaria da Educação e do Estado para com os professores: oferecer uma formação totalmente voltada para as práticas em sala de aula, proporcionando melhor aprendizagem aos alunos. Nesse sentido,

trata-se de formar para a inovação pessoas capazes de evoluir, de se adaptar a um mundo em rápida mutação e de dominar a mudança. Faz-se necessário um trabalhador e uma trabalhadora que, como saber fazer, saiba pensar, portanto, tenha um nível elevado de escolarização e uma atitude de formação permanente, cujas habilidades de aprender a aprender e de trabalhar em equipe atuem como fio condutor. (Zabala, 2002, p. 57)

Assim, a Secretaria da Educação do Tocantins entende que o professor é o profissional que mais precisa se manter atualizado. Transformar essa necessidade em direito é fundamental para o alcance da própria valorização profissional e desempenho em patamares de competência exigidos pela sua função social. É importante ressaltar que essa atualização por si só não basta - é preciso a transposição de conhecimentos e procedimentos metodológicos que mais se adéqüem as realidades da sala de aula. 
Tardif (2002) inclui, no saber docente, características como o estar sempre ligado a uma situação de trabalho com os outros - alunos, colegas, pais - e, além disso, estar ancorado numa tarefa complexa que é o ensino, situado num espaço próprio de trabalho, enraizado numa instituição e numa sociedade. Essas particularidades o situam na interface entre o indivíduo e o social, e essa interface pode ser entendida por meio da análise de diferentes fios condutores, como: o saber e o trabalho, a diversidade do saber, a temporalidade do saber, e a experiência.

Essas categorias assumem maior importância como fundamentos para se pensar a formação de professores, se esta se configura em uma proposta de trabalho colaborativo envolvendo formadores das universidades e das escolas. Nessa perspectiva, como pensar os chamados conhecimentos escolares, cuja origem está na elaboração das ciências, das tecnologias, da filosofia e das artes? Como potencializar a reflexão valendose de uma base de conhecimentos para o ensino?

O conhecimento é enraizado na vida social, expressando e estruturando a identidade e as condições sociais dos que dele partilham. Por isso, ações sociais ou educacionais que têm por objetivo criar condições de mudanças conceituais, de atitudes e práticas precisam estar engrenadas com o meio sociocultural no qual as pessoas, os profissionais, que serão abrangidos por essas ações, vivem (Gatti, 2003).

Estima-se que durante o processo de formação continuada o professor possa confrontar os conhecimentos matemáticos, desenvolver novas habilidades, crescer profissionalmente, trabalhar sempre no coletivo, adquirir hábitos para leitura e pesquisa e sobretudo, aperfeiçoar a prática em sala de aula e ter uma visão mais ampla da escola, principalmente sob o aspecto da gestão da mesma.

A Matemática precisa ser aprendida de forma dinâmica, por meio de jogos, modelagem, situações lúdicas, investigações e refutações. Se o professor não teve nenhuma situação semelhante como experiência em sala de aula como aluno, ele precisa buscar novas situações que possibilitem seu crescimento profissional e a valorização. Esse crescimento pode e deve ser adquirido nos momento de formação.

Segundo D`Ambrósio (1993, p. 240), "é absolutamente inadmissível que o professor continue ministrando uma ciência acabada, morta e desatualizada. Será cada vez mais difícil motivar alunos a estudar uma ciência do passado, cristalizada". Nesse sentido, percebe-se que o professor precisa internalizar os conceitos, práticas, métodos, dinâmicas e jogos durante sua formação inicial e contínua, colocando em prática na sala de aula. Entre os efeitos esperados destaca-se a capacidade de contribuir efetivamente, para uma gestão democrática participativa, na qual o professor ministra os conteúdos, troca experiências e conhecimentos adquiridos com os alunos, participa do processo de gestão e adquire habilidades para juntos resolverem situações - problemas do dia-a-dia tornando-os capazes de construir um raciocínio lógico em cada situação vivenciada no contexto familiar, na rua, na escola, bem como no cenário da vida enquanto ser social e cultural no meio em que vive.

Assim sendo, a Secretaria Estadual da Educação desenvolve um programa de formação continuada dirigida aos professores de Matemática, com vistas a apresentar metodologia do ensino de Matemática não fragmentada, mas dinâmica, contextualizada e que esteja em consonância com o universo tecnológico, que possa motivar os professores e os alunos a estudarem uma ciência do presente voltada para o século 21 . 
É dever do Estado a garantia do direito à educação de qualidade, estabelecido na Constituição Brasileira de 1988, na Lei de Diretrizes e Bases da Educação Nacional e no Plano Nacional de Educação, considerando direito social e com estatuto de direito humano consignado na Declaração Universal dos Direitos Humanos de 1948 e no Plano Internacional de Direitos Sociais Econômicos e Culturais de 1966. Cabe, portanto, verificar como tem sido historicamente, a postura do Estado brasileiro no cumprimento de seu dever.

Para garantir a Constituição, a escola tem se tornado uma organização social constituída pela sociedade para cultivar e transmitir valores sociais elevados e contribuir para a formação de seus alunos, mediante experiências de aprendizagem e ambiente educacional condizentes com os fundamentos, princípios e objetivos da educação. Os seus ambientes são considerados importantes para o fortalecimento e o desenvolvimento de aprendizagens significativas que possibilitem aos alunos conhecerem o mundo e conhecerem-se no mundo, como condição para o desenvolvimento de sua capacidade de atuação cidadã (Lück, 2007).

Nesse contexto, os alunos são as pessoas para quem a escola existe e para quem deve voltar as suas ações, de modo que todos tenham o máximo sucesso nos estudos que realizam para sua formação pessoal e social. Para tanto, eles devem ser envolvidos em ambientes e experiências educacionais estimulantes, motivadoras e de elevada qualidade, que os levem ao desenvolvimento de seu potencial, o prazer e hábito de aprender. Esse deve ser o foco principal da escola.

Os professores, por sua vez, são os profissionais que influenciam diretamente na formação dos alunos, a partir de seu desempenho baseado em conhecimentos, habilidades e atitudes e, sobretudo, por seus horizontes pessoais, profissionais e culturais, bem como sua postura diante da vida, dos desafios, da educação e das dificuldades do dia-a-dia encontradas na sala de aula como professor.

A educação é um processo organizado, sistemático e intencional, ao mesmo tempo em que é complexo dinâmico e evolutivo, em vista de que demanda não apenas um grande quadro funcional, como também a participação da comunidade, dos pais e de organizações diversas, para efetivá-lo com a qualidade necessária que a sociedade tecnológica da informação e do conhecimento demanda (Lück, 2007).

Portanto, percebe-se que o desenvolvimento da competência - habilidades e atitudes - é de vital importância para todos que atuam em educação, como condição de aprimoramento de sua identidade profissional, baseada em promoção de resultados cada vez mais eficazes e capacidade de responder efetivamente, aos desafios sempre novos da educação.

Possuir conhecimentos ou determinadas capacidades não é o bastante para garantir que um profissional seja competente. Muitos profissionais que possuem conhecimentos ou capacidades importantes nem sempre sabem mobilizá-los de modo adequado, aplicando-o no momento oportuno (Perrenoud, 2000).

Conforme a LDB define, é de competência dos professores, além de outros aspectos: participar efetivamente, da elaboração da proposta pedagógica da unidade de ensino a qual atua, elaborar e cumprir com o seu plano de trabalho, proporcionar momentos de aprendizagem para os alunos, estabelecer criteriosamente estratégias de recuperação para os alunos com menor rendimento, cumprir e ministrar os dias letivos e 
horas-aulas estabelecidos, participar integralmente e discutir coletivamente os resultados da avaliação nacional, colaborar com as atividades de articulação da escola com as famílias e a comunidade a qual está inserida.

Para garantir o que propõe a LDB, pensa-se que a capacitação em serviço, no contexto escolar, se constitua em um plano sistemático e abrangente, pelo qual são definidos os objetivos, estratégias e atividades organizadas para esse fim e que sejam propostas ações de monitoramento e avaliação dos resultados.

\section{A gestão da formação continuada dos professores de matemática}

Especificamente quanto às práticas de formação de professores, a tendência investigativa mais recente e mais forte è a que concebe o ensino como atividade reflexiva. Trata-se de um conceito que perpassa não apenas a formação de professores como também o currículo, o ensino, a metodologia de docência. A idéia é a de que o professor possa pensar sua prática, ou em outros termos, que o professor desenvolva a capacidade reflexiva sobre sua própria prática.

O movimento da prática reflexiva atribui ao professor um papel ativo na formulação dos objetivos e meios do trabalho, entendendo que os professores também têm teorias que podem contribuir para a construção de conhecimentos sobre o ensino (Zeichener, 1993).

Segundo Imbernóm (2009), é preciso revisar criticamente essas práticas reflexivas, os conteúdos e os processos da formação permanente do professor para que gerem um conhecimento profissional ativo e não passivo, e não dependente de um conhecimento externo nem subordinado a ele.

Pensando nessas práticas e com o objetivo de contribuir para uma discussão que venha nortear o processo de formação continuada, os professores propiciaram momentos satisfatórios respondendo as questões propostas no questionário. Para esse fim, foi proposto pelos próprios professores o horário de aulas atividades para a realização e conclusão desse trabalho.

\section{Como acontece a gestão do processo de formação continuada dos docentes em Matemática?}

Em contexto geral, foram respondidos claramente que, até o ano de 2009, quando a Secretaria da Educação do Tocantins estabeleceu parceria com a Fundação Cesgranrio, a política de implantação e implementação da formação continuada acontecia de forma sistemática, organizada, contemplando um bom planejamento das ações a serem desenvolvidas. Outro aspecto fundamental para o sucesso dos encontros era o apoio da gestão pedagógica da escola e da Seduc, sobretudo, ancorada na boa gestão dos procedimentos. Durante o curso percebeu-se, por meio de instrumentos avaliativos, um avanço considerável na prática docente em sala de aula, objetivo maior da formação continuada. Até então os estudos realizados eram pensados, planejados, orientados e direcionados à prática efetiva da sala de aula, infelizmente essa boa prática não demorou 
muito tempo, logo veio o término da então parceria Seduc/Cesgranrio ${ }^{1}$ e a partir daí, houve uma pausa em todo processo.

Logo em seguida, com método similar, iniciou-se com a introdução do Gestar². No entanto, em razão da transição política ocorrida nesses três últimos anos no Estado, se enfraqueceu a gestão do processo de formação contínua dos profissionais em Matemática. Percebe-se que, no momento, não acontece de forma satisfatória o processo de gestão da formação continuada em Matemática e isso tem influenciado para a não motivação da prática docente em sala de aula.

\section{Em quais aspectos a formação continuada tem contribuído para o fortaleci- mento da gestão educacional?}

Acredita-se que tenha contribuído no fortalecimento das práticas pedagógicas, tanto no tocante a gestão educacional, como na prática em sala de aula. Não temos dúvidas de que o aspecto mais importante é a capacidade de mudanças nas atitudes do professor, no comportamento dentro e fora da escola, na relação interpessoal, no envolvimento e participação nas ações da escola e da comunidade, na resolução de conflitos entre alunos, professores e servidores da educação, no envolvimento da gestão democrática, na escolha do diretor, acompanhamento dos recursos financeiros e tecnológicos, participação efetiva no processo de elaboração da proposta pedagógica da escola, planejamento participativo, além de habilidades e reflexões, que nos auxiliam todos os dias na sala de aula.

Outro aspecto bem visível de mudança desses profissionais refere-se à utilização dos instrumentos tecnológicos e das ferramentas de acompanhamento e monitoramento relatórios, fichas de acompanhamento, diário de classe, plano de curso, etc. - da escola, das Diretorias Regionais de Ensino e da Secretaria da Educação, que servirão de material de apoio para elaboração e implementação de políticas educacionais que possam fortalecer efetivamente, a gestão educacional e a prática docente em sala de aula.

\section{A gestão do processo de formação continuada corresponde aos seus anseios e expectativas enquanto professor?}

Muitas críticas foram feitas em relação ao tempo de permanência na realização dos encontros - apenas um dia de efetiva atividade em cada encontro. Boa parte dos professores julgaram insuficiente para abordar muitos conteúdos programados, enquanto outros reclamaram da não adequação do caderno de exercício aos conteúdos da proposta curricular seqüenciada pela Secretaria da Educação do Estado do Tocantins.

Quanto à metodologia - lista de exercícios para resolução - utilizada nos seminários e encontros presenciais, alguns professores consideraram as atividades repetitivas, preferindo mais aulas práticas, por exemplo: oficinas e aulas em laboratórios de informática. Outro aspecto negativo que desestimulava a equipe estava nos ambientes não climatizados, salas de aula lotadas, com muito barulho, o que prejudicava o desempenho.

\footnotetext{
1 Empresa de consultoria contratada pela Secretaria da Educação do Tocantins para desenvolver uma política de formação continuada dos profissionais em educação, especificamente, professores licenciados e docentes em matemática que atuam na rede estadual.

2 Gestar: programa de formação continuada que tem como finalidade melhorar as práticas em sala de aula, gestão pedagógica, qualidade de ensino e a aprendizagem dos alunos.
Santa Maria
v. 2
ก. 4
Jul./dez. 2013
p. $93-105$

Regae: Rev. Gest. Aval. Educ.
} 
Apesar das críticas mencionadas e os pontos negativos apresentados, uma quantidade considerável dos professores entrevistados, quatro deles, respondeu de forma satisfatória, considerando a formação como um processo histórico, positivo e contínuo. Perceberam-se profundas resistências por se tratar de professores de diversos Estados brasileiros, diferentes regiões do país. Cada profissional entendia que sua prática era inovadora, suas experiências desde a formação inicial eram suficientes e adequadas em qualquer espaço e para qualquer aluno.

Os encontros de formação serviam muito mais para reflexão do que para a quebra desses paradigmas. Durante os momentos de discussão surgiam muitas dúvidas, tais como: "tenho dez anos de experiência e não pretendo mudar, já aprendi tudo o que tinha de aprender, me formei em uma universidade pública e era a melhor" (relato de professores). Passo a passo essa resistência foi desaparecendo, dando espaço para interação social e cultural E possibilitando maior entendimento e desenvolvimento para uma prática reflexiva voltada para a diversidade e para uma gestão educacional de sucesso. Nota-se que os resultados desse trabalho precisam ser apresentados, acreditados e vistos como ações de sucesso. Verifica-se, pelo desempenho dos alunos, que o saldo é positivo, o professor tem avançado como profissional, a escola tem conseguido realizar um planejamento mais eficaz, procurando contemplar e inserir nesse processo os alunos, os profissionais da educação e a comunidade.

Outra parte dos professores respondeu que não, ponderando a quebra no processo de gestão da formação continuada, entendimento já mencionado e explicado como mudanças na Política Tocantinense, mas fazem menção ao que garante a LDB no art. $2^{\circ}$. A educação constitui-se nos processos formais e organizados, realizados nas escolas, com a finalidade de promover o desenvolvimento pleno do educando, sua preparação para o exercício da cidadania e sua qualificação para o trabalho. Diante do que garante a LDB, lamentavelmente, nos últimos três anos a gestão tem deixado a desejar em relação ao processo de gestão educacional e da formação continuada. Hoje entendemos que precisamos nos transformar para poder tentar transformar as pessoas e o mundo, criar novas concepções de ensino, encontrar novas técnicas que propicie a aprendizagem dos alunos.

\section{O processo de formação continuada tem contribuído para a melhoria de sua prática em sala de aula?}

Boa parte dos professores afirmou que, mesmo considerando os pontos críticos durante os encontros, a formação continuada tem seu lado positivo. Em relação a essas contribuições da prática em sala de aula, quando a formação continuada é pensada, planejada e executada objetivando a melhoria das práticas docentes. Evidentemente, que o processo se tornará eficaz e os reflexos percebidos na escola e na sala de aula também, apesar de alguns desencontros durante o processo. $O$ mais importante e que não podemos perder de vista, é que, o processo de formação deve ser inovador, necessariamente, precisa ser contínuo.

Percebemos que, quando o processo é pensado como estratégia com objetivos claros, torna-se primordial para o fortalecimento das práticas pedagógicas e melhoria na implantação e implementação das políticas educacionais, os resultados positivos e os frutos, certamente serão colhidos ao longo da história.

\begin{tabular}{l|l|l|l|l|r|} 
Regae: Rev. Gest. Aval. Educ. & Santa Maria & v. 2 & n. 4 & Jul./dez. 2013 & p. 93-105
\end{tabular}


Entendemos que é pela formação e valorização profissional que o professor enxergará outros horizontes, buscará novos caminhos para desempenhar a função, terá mais compromisso pelo seu trabalho e pela administração escolar, será um profissional mais acessível aos alunos e colegas de trabalho, possibilitando assim, mudanças no comportamento pessoal, cultural, social e o enfrentamento dos novos desafios da profissão e a busca contínua por outros cursos de aperfeiçoamento profissional.

É importante lembrar que, o professor só terá um bom desempenho, quando tiver um tempo suficiente para o planejamento das aulas, tempo para pesquisar e se aperfeiçoar tecnologicamente, pois, os alunos têm muito mais conhecimentos de tecnologia do que o professor, o qual tem que avançar em relação ao uso dos instrumentos tecnológicos.

Observamos que todo esse processo de gestão educacional e da política de formação continuada oferecida aos professores de matemática, percebe-se que tem contribuído para o fortalecimento de uma gestão participativa, democrática e descentralizada. No entanto, referente à capacitação profissional não tem seguido o que orienta Lück (2004) quando diz que o processo precisa ser organizado, sistemático, visando à promoção e a valorização profissional, pensa-se que é preciso avançar mais nas discussões no que se entende como "programa" ou "treinamento" para capacitação e valorização profissional.

Entende-se, segundo Perrenoud (2000) que a formação do professor, está diretamente interligada a sua prática do dia-a-dia em sala de aula, nesse sentido, faz-se necessário uma reorganização dessas políticas de formação. Possivelmente, os anseios, necessidades e expectativas dos professores ainda não foram atingidas, de forma satisfatória, justifica-se tal situação por se tratar de um processo em construção.

De acordo com as reflexões de Pimenta (2002), Zabala (2002), Tardif (2002) e Gatti (2003), constam a necessidade da formação continuada acontecer em exercício para a inovação do profissional, de momentos de discussão com alunos, pais e outros profissionais, proporcionando condições para possíveis mudanças no contexto escolar. Percebe-se que é esse modelo de proposta que os professores esperam da Secretaria da Educação.

\section{Considerações finais}

Esse trabalho de pesquisa desenvolveu-se com a colaboração de dez professores licenciados em Matemática, que atuam no ensino médio estadual em Palmas/TO e lecionam no turno noturno. O objetivo principal dessa pesquisa foi o de tentar entender como acontece a gestão do processo de formação continuada dos professores de Matemática. Os resultados apresentados demonstram que alguns professores não se adaptaram à nova metodologia implantada a partir da política de formação continuada proposta pela Secretaria da Educação do Estado do Tocantins.

Para muitos profissionais em educação, o método tradicional tem sido a principal metodologia usada no ensino da Matemática. Esta realidade pode ser constatada no dia a dia de nossas escolas. Este fato está diretamente ligado com a formalização do ensino desta ciência, que ao longo dos tempos não se modificou, mesmo com as transformações sofridas no mundo do conhecimento. 
Sabemos que não se muda a educação apenas do lado da oferta, é preciso, também, que o professor seja instrumentalizado por cursos profissionalizantes e de formação continuada para demandar ensino e uma gestão educacional de qualidade. Autonomia e flexibilidade devem fazer parte no âmbito da escola, no sentido de oferecer alternativas para trabalhar a interdisciplinaridade adaptadas às realidades locais, da escola e principalmente da sala de aula, sabendo-se que a educação é o caminho mais eficaz para a construção da consciência dos direitos e deveres das pessoas.

A profissionalização, portanto, deve assegurar conteúdos que propiciem a compreensão do papel e a inserção da escola no sistema educacional, assim, como a relação entre as diversas instâncias do poder público. Vale ressaltar que, o processo de construção da gestão democrática na escola, o processo de construção do Projeto Político Pedagógico e a participação dos diversos segmentos escolares - alunos, professores, colaboradores, voluntariados, pais, comunidade local, igrejas, grêmio estudantil e os conselhos escolares -, necessariamente, devem estar presentes para que aconteça o sucesso dos alunos e dos profissionais em educação, a promoção social e cidadã e a construção da verdadeira identidade da escola.

Percebe-se, que este propósito já vem acontecendo em algumas escolas de Palmas - Tocantins, uma vez que os resultados esperados com a implantação da política afirmativa de formação continuada já estão aparecendo, isso é notável através dos depoimentos dos professores e a prática docente em sala de aula, além de que cada profissional recebeu um notebook que permite acesso a internet, viabilizando um melhor planejamento e aulas mais dinâmicas. Tudo isso tem contribuído para uma gestão participativa, mais democrática, maior envolvimento dos professores no planejamento escolar, conselhos escolares atuantes e melhor aplicabilidade dos recursos descentralizados a gestão. São esses resultados positivos que reafirmam a proposta de formação continuada aos profissionais da educação do Tocantins.

\section{Referências}

ALMEIDA, Manoel de Campos. Origens da matemática. Curitiba: Universitária, 1998.

BRASIL. Presidência da República. Lei n. 9.394 de 20 de dezembro de 1996 - Estabelece as Diretrizes e Bases da Educação Nacional. Publicada no Diário Oficial de 23 de dezembro de 1996. Disponível em: <http://www.planalto.gov.br/ccivil_03/Leis/9394.htm>. Acesso em: 4 abr., 2011.

CARVALHO, Maria Lúcia R. D. Escola e democracia. São Paulo: EPU, 1979.

CONSED. Manual do prêmio nacional de referência em gestão escolar. Ciclo Ano Base 2006. Brasília: Consed, 2007.

CHIZZOTTI, Antonio. Pesquisa em ciências humanas e sociais. São Paulo: Cortez, 2006.

D`AMBRÓSIO, Ubiratan. A matemática na época das grandes navegações e início do da colonização. Revista Brasileira de História da Matemática, v. 1 n. 1, 2001, $12-20$

D`AMBRÓSIO, Beatriz Silva. Formação de professores de matemática para o século XXI: o grande desafio. Pro-posições, v. 4, n. 1, 1993, p. 39-40.

D`AMBRÓSIO, Beatriz Silva. Conteúdo e metodologia na formação de professores. In: FIOENTINI, Dario; NACARATO, Adair Mendes. (orgs.). Cultura, formação e 
desenvolvimento profissional de professores que ensinam matemática: investigando e teorizando a partir da prática. São Paulo: Musa, 2005, p. 13-17.

D`AMBRÓSIO, Ubiratan (org.). O ensino de ciências e matemática na América Latina. Campinas: Unicamp, 1984.

GATTI, Bernadete Angelina. Formação continuada de professores: a questão psicossocial. Cadernos de Pesquisa, v. 1, 2003, p. 196-197.

LÜCK, Heloísa. Planejamento em orientação educacional. Petrópolis: Vozes, 2008.

LÜCK, Heloísa. Liderança em gestão escolar. Petrópolis: Vozes, 2008.

LÜCK, Heloísa. Gestão educacional: uma questão paradigmática. Petrópolis: Vozes, 2007.

LÜCK, Heloísa. Ação integrada: administração, supervisão e orientação educacional. Petrópolis: Vozes, 2007.

LÜCK, Heloísa. A capacitação dos profissionais de educação de Pinhais e suas mãos. Pinhais: Semed, 2004.

LÜCK, Heloísa. Gestão educacional: estratégia para a ação global e coletiva no ensino. Gestão em rede, 1997, 36-38.

PAVANELLO, Regina Maria; ANDRADE, Roseli Nozaki Grave. Formar professores para ensinar geometria: um desafio para as literaturas em matemática. Educação Matemática em Revista, v. 9, n. 11, 2002, p. 78-86.

PERRENOUD, Philippe. Dez novas competências para ensinar. Porto Alegre: Artes Médicas Sul, 2000.

TARDIF, Maurice. Saberes docentes e formação profissional. Petrópolis: Vozes, 2002.

ZABALA, Antoni. A prática educativa. Porto Alegre: ArtMed, 1998, p. 24-38.

ZABALA, Antoni. Como trabalhar os conteúdos procedimentais. Porto Alegre: Artes Médicas, 1999.

ZABALA, Antoni. Enfoque globalizador e pensamento complexo: uma proposta para o currículo escolar. Porto Alegre: Artmed, 2002.

VIGOTSKI, Lev Semyonovich. A formação social da mente. São Paulo: Martins Fontes, 1989.

Severino Roberto de Lima é licenciado em Ciências com Habilitação em Matemática pela Faculdade de Formação de Professores de Goiana/PE em 2000. Especialista em Gestão Educacional pela UFSM/RS em 2011. Atualmente é diretor de Administração da Secretaria Estadual da Educação e Cultura do Estado do Tocantins.

Endereço: Quadra 606 Sul, Al Ceshiciatti, QI 10, LT 08 CS 02 - 77022-076 - Palmas - TO - Brasil.

E-mail: robertolm44@gmail.com.

Recebido em 18 de setembro de 2013.

Aceito em 21 de outubro de 2013. 